\title{
Analysis of microseismic cluster locations based on the evolution of mining-induced stresses
}

\author{
S Shnorhokian McGill University, Canada \\ HS Mitri McGill University, Canada \\ L Moreau-Verlaan Vale Canada Ltd., Canada
}

\begin{abstract}
Numerical modelling is increasingly being used in the mining industry as part of the planning process. Its areas of application range from the estimation of in situ stresses at planned locations of underground facilities, to the effects of stope sequence alternatives on drift instability. In terms of the size of their study area, numerical models can range from a section of a given level to mine-wide dimensions, with an increase in complexity and input information requirements. Microseismic activities induced by mining operations can be studied using mine-wide numerical models that have been properly calibrated. In this paper, mining-induced seismicity at the Vale Garson Mine is examined between 2006 and 2008 with a numerical model constructed in FLAC3D. Two sets of microseismic activities are used as a basis of the study; events from the microseismic database with energy outputs greater than $100 \mathrm{~kJ}$, and events that have resulted in rockbursts within developments, regardless of their energy outputs, for a total of 24 events. In the first phase of the study, the coordinates and location error of each event, as obtained from the microseismic database, are used to construct a location cube defining the maximum boundaries within which the actual coordinates must lie. Based on the 24 location cubes plotted, four microseismic clusters are identified. In the second phase, the mine-wide model is calibrated based on laboratory results of rock samples, borehole data of rock mass properties, and an in situ stress measurement point on $4900 \mathrm{~L}(1,495 \mathrm{~m})$. The historical stope sequence followed at the mine is replicated in the model from 2001 to 2008. Mining-induced stresses within the location cubes of two clusters are examined using the maximum shear stress, brittle shear ratio, and the continuous change in differential stress (CC-DS) when compared to pre-mining conditions. It is shown that all event location cubes studied register an abrupt increase in CC-DS some time before or during the occurrence of that event. In the final phase, the most microseismically active zone in one of the geological units is compared to relatively quiet zones in terms of CC-DS conditions. It is shown that the CC-DS values are mostly constant in the latter zone, while they typically undergo abrupt and sudden changes in the active one prior to microseismic events. Hence, a new method of analysis with the potential of predicting the location of microseismic clusters is introduced.
\end{abstract}

\section{Introduction}

Mining-induced seismicity is an important issue for the industry and academic community since it has a significant impact on mining operations and the safety of personnel. Due to advances in technology and extraction methods, and with the depletion of shallower deposits, mining is projected to increasingly take place at greater depths. This translates into higher stress environments and an increase in the frequency and magnitude of seismic activities associated with mining operations. Extensive research has been conducted within the past decades on the topic, with regular updates to researchers and the industry (Gibowicz 1990; Gibowicz \& Lasocki 2000). A rich collection of case histories (McGarr et al. 2000), and overviews on a national level (Hasegawa et al. 1989; Spottiswoode 1989) exists for mining-induced seismicity and rockbursts, which constitute the most dangerous by-product of this phenomenon. The main mechanism underlying mining-induced seismicity has been determined to be readjustment of stresses due to the creation of vast openings underground in the form of stopes (Cook 1976), and the action of shear stress on fractures (Jaeger et al. 2007; Brady \& Brown 2006; Verdon et al. 2011). 
With respect to numerical modelling approaches associated with mining-induced seismicity, also called microseismicity due to its relatively low magnitude when compared to earthquakes, the usual trend is to use the microseismic activity at the site as a basis for calibrating the numerical model. However, there have been a number of studies that have combined numerical modelling and microseismic analysis to solve practical problems in the field as well. Hazzard and Young (2004) have discussed numerical modelling with a particle flow code (PFC2D) in relation to actual field seismicity. Mercer and Bawden (2005a, 2005b) have employed a statistical approach on seismic data from the Creighton Mine in Sudbury (Canada). McKinnon (2006) has studied triggered seismicity in the Sudbury region that occurs along faults at a distance from excavations. Event clusters at the Creighton Mine have been examined by Marsan et al. (1999). In France, Abdul-Wahed et al. (2006) have applied numerical modelling to an analysis of rockbursts at a coal mine. An extended review of microseismicity and numerical modelling has been carried out by Castro et al. (2012).

In this paper, a combined microseismic and numerical modelling analysis is conducted for the Vale Garson Mine in Sudbury. Events from the microseismic database and mine rockburst reports are examined for the presence of spatial clusters, and their locations are then analysed for changes in mining-induced stresses using a mine-wide numerical model.

\section{Garson Mine}

The case study for this paper is Vale's Garson Mine in Sudbury, which has been in operation for more than 100 years. The geology of the Sudbury Basin area is dominated by the series of formations designated as the Sudbury Igneous Complex, and the mine is located at the southeast corner of the Basin. The deposits are mainly copper-nickel sulphides and are concentrated in two main orebodies designated as \#1 Shear and \#4 Shear, which are located at a depth of 1,200-1,700 m, striking generally east-west and dipping $60-75^{\circ}$ to the south. The sheared host rocks are made up of metavolcanics and greenstone formations with norites to the north and metasediments to the south.

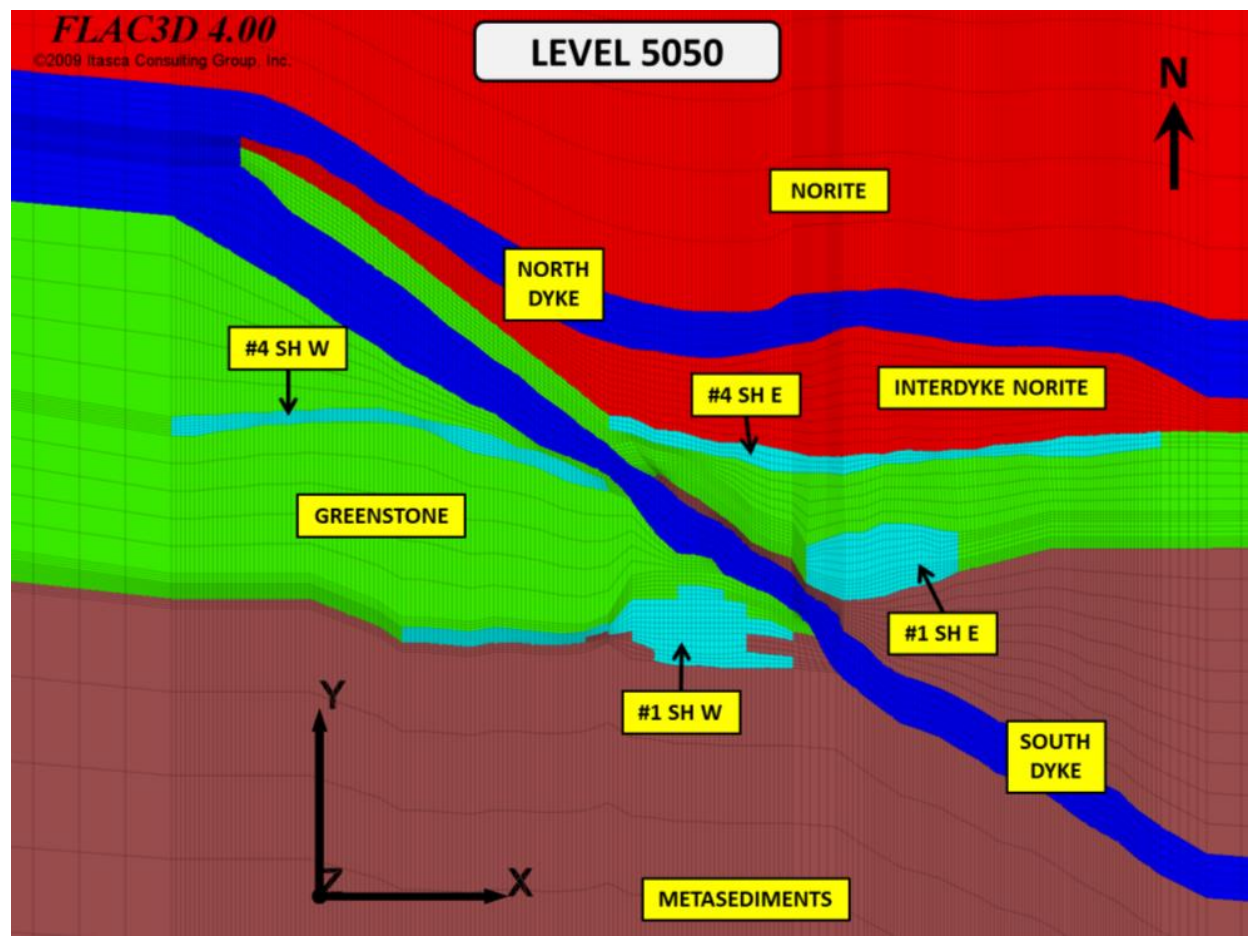

\section{Figure 1 Geological formations at the Garson Mine on 5050L of a mine-wide model}

All geological units are offset by a swarm of olivine diabase dykes in a northwest-southeast trend and one of them runs through the mine. The dyke has an average thickness of $30 \mathrm{~m}$ and separates into northern and southern limbs prior to approaching the orebodies from the northwest. The north dyke runs parallel to the orebodies above the \#4 Shear, but the south dyke continues its northwest-southeast trend, dividing them 
into western and eastern sections. A shear zone about $15 \mathrm{~m}$ in width, and designated as 2500 Shear, runs northwest-southeast at an almost parallel orientation and close to the south dyke. The geological setting is shown in Figure 1 on 5050L (1,540 m) of a mine-wide model constructed in FLAC3D (Itasca Consulting Group, Inc. 2014).

\section{$3 \quad$ Microseismic analysis}

Microseismic monitoring is conducted at Garson Mine with a Paladin system employing uniaxial accelerometers, in addition to a surface ground motion sensor. It assigns northing, easting, and elevation, local and moment magnitudes, energy, Es:Ep (ratio of energy from secondary waves to that from primary ones), and a date/time stamp to each event source, which are stored in a continuous database. For the purposes of this study, the data for the years 2001 to 2011 was obtained for analysis, and combined with rockburst and fall-of-ground reports kept at the mine. Due to equipment upgrades in 2006, better quality data is observed from that year onwards when compared to the previous years. Since a number of rockbursts took place at the mine in 2008, the microseismic analysis is therefore confined to the years 2006 to 2008 , inclusive.

\subsection{Significant events}

There are two groups of data on which the microseismic analysis is based. Firstly, an assessment is made of the microseismic database between 2006 and 2008 and the energy outputs associated with the recorded events. Based on the distribution of these values for the entire dataset, events registering greater than $100 \mathrm{~kJ}$ are designated as large and selected for further analysis. Out of this set, events with location errors greater than $30 \mathrm{~m}(100 \mathrm{ft})$ are discarded because the potential volume of their true location is too large to be considered in any spatial analysis. Secondly, and based on a combined mine rockburst reports and microseismic database analysis, events identified as having triggered rockbursts are selected for further analysis and designated as rockburst-causing events. It should be noted that these events only represent the source location of the associated microseismic event, while the actual rockbursts and ejection of material occur elsewhere near underground openings such as stopes or developments. These two groups together constitute the main set of significant microseismic activities analysed in this paper.

\subsection{Spatial and temporal distributions}

The set of significant microseismic events compiled is analysed in terms of location to verify if a certain geological formation is more susceptible to activity than others. In addition, the timing is studied to look for a relationship to mining operations in the vicinity. The phenomenon of event clustering has been studied in detail in the literature and a number of researchers conclude that event clusters can be used to designate regions of high microseismic activity (Bewick et al. 2009; Hudyma 2008; Kijko \& Funk 1996; Mendecki 1997; Mikula et al. 2008; Vasak et al. 2004). In this study, both rockburst-causing and large events (LE) are plotted using their main coordinates as recorded by the monitoring system, and the presence of spatial clusters is examined for indications of microseismically active zones. The proximity of events to mining fronts during active periods is indicative of the effects of stress readjustments caused by stope extraction. Therefore, as part of the analysis, the volume of ore mined in the vicinity of significant events is also calculated, based on the historical mining sequence implemented between 2001 and 2008.

\section{$4 \quad$ Numerical modelling}

In addition to microseismic analysis, a numerical modelling approach is also utilised in this study. A mine-wide numerical model is constructed in the finite difference code FLAC3D comprising all the geological formations found at the site. The model extends vertically from $5100 \mathrm{~L}(1,555 \mathrm{~m})$ to $4470 \mathrm{~L}(1,360$ $\mathrm{m}$ ) and is constructed based on the plan maps of the levels in between. In order to have the boundaries far from any excavations, the vertical limits are extended to $5500 \mathrm{~L}(1,675 \mathrm{~m})$ at the bottom and to $3500 \mathrm{~L}$ $(1,070 \mathrm{~m})$ at the top. The remaining dimensions are $915 \mathrm{~m}$ in the east-west direction and $760 \mathrm{~m}$ in the north-south one, with a total of 1.15 million zones. In order to accentuate the brittle behaviour inherent in 
microseismic activity and maximise the mining-induced stresses, the model is run in linear elastic mode and is calibrated by a correlation with in situ stress measurements conducted on $4900 \mathrm{~L}(1,495 \mathrm{~m})$ (Maloney \& Cai 2006), using boundary tractions to generate the pre-mining stresses.

\subsection{Mining front}

The majority of microseismic events at mines are usually triggered because of stress readjustments caused by ore extraction (strainbursts), while a smaller group occurs due to movement along discontinuities (faultslip). Therefore, the historical stope sequence followed at the mine from 2001 to 2008 is replicated in the mine-wide model, and stope extraction is modelled in periods of three months. The significant events are plotted and the presence of spatial clusters identified from the microseismic analysis is verified. The stopes closest to the clusters are selected and their total volumes are calculated from the model geometry. Based on this information, the percentage of extracted nearby stopes is monitored at each stage and compared to the timing of the events within the nearby cluster for any correlations.

\subsection{Mining-induced stresses at cluster locations}

\subsubsection{Differential stress indicators}

The potency of a mine-wide numerical model is its ability, once it is calibrated based on in situ stresses or displacements, to calculate mining-induced stress changes caused by stope extraction. Since microseismic events are triggered mostly by stress readjustments, the first step in the numerical analysis is to examine the state of stress at the significant event locations throughout the study period. A number of criteria have been suggested in the literature that can be used to monitor potential triggers. The literature indicates that one of the initiation mechanisms of microseismicity is through shear along fractures and cracks (Jaeger et al. 2007; Brady \& Brown 2006; Verdon et al. 2011). Therefore, the maximum shear stress at the event locations would be an important criterion to monitor, which is in essence half the differential stress - the difference between the maximum and minimum principal stresses - and is given by:

$$
\text { Maximum shear stress }=\left(\sigma_{1}-\sigma_{3}\right) / 2
$$

A second criterion discussed in the literature relates the differential stress $\left(\sigma_{1}-\sigma_{3}\right)$ to the unconfined

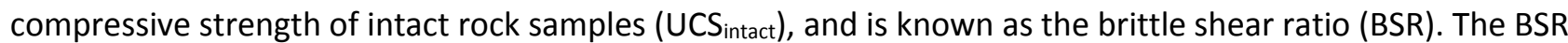
is used mainly in the vicinity of underground openings as an indicator of fracture development within intact rock mass and strainbursts (Brace et al. 1966; Castro 1996; Castro et al. 2012; Castro et al. 1997; Diederichs 1999; Martin 1997; Martin and Chandler 1994), and is calculated by:

$$
\operatorname{BSR}=\left(\sigma_{1}-\sigma_{3}\right) / U C S_{\text {intact }}
$$

The maximum shear stress and the BSR are related to one another since they are both based on the differential stress $\left(\sigma_{1}-\sigma_{3}\right)$. Researchers have concluded that cracks are initiated within intact samples when they reach $25 \%$ to $40 \%$ of their peak unconfined compressive strength (Brace et al. 1966; Castro et al. 1996; Martin et al 1999), and others have found damage zones at differential stress levels exceeding $120 \mathrm{MPa}$ (Wiles et al. 2001). Regarding the BSR, it has been stated that values exceeding 0.7 are indicative of major strainbursts (Castro et al. 2012), a threshold that is also used by Vale.

The maximum shear stress and BSR are recognised parameters for initiating microseismicity. However, they could inadvertently convey an impression of being static parameters that are only to be assessed following the occurrence of an event. Even when used as thresholds to monitor microseismicity, their role could intuitively be thought of as being quasi-static, alerting the system when readings approach these thresholds only. In reality, the maximum shear stress and BSR incorporate the differential stress $\left(\sigma_{1}-\sigma_{3}\right)$, which is a dynamic component in a mining context, as it continuously evolves with each extraction and backfilling stage. Since microseismicity is induced by changes in the stress regime, and the differential stress is an integral part of both maximum shear stress and BSR, a new parameter is introduced that continuously monitors these changes. The continuous changes in differential stress (CC-DS) compares the $\left(\sigma_{1}-\sigma_{3}\right)$ value at a given stage to the pre-mining value at that location. Since this is done continuously at each stage, the 
overall trend of the plotted data remains constant and sudden changes are easily identified. The CC-DS is given by:

$$
\% \text { CC-DS } S_{\text {tage } 1}=\left[\left(\sigma_{1}-\sigma_{3}\right)_{\text {stage } 1}-\left(\sigma_{1}-\sigma_{3}\right)_{\text {pre-mining }}\right] \times 100 /\left(\sigma_{1}-\sigma_{3}\right)_{\text {pre-mining }}
$$

Due to the fact that the CC-DS value represents the relative change at a given stage from the pre-mining value, it is numerically equal to the percentage change in maximum shear stress and the percentage change in BSR at that same stage. Hence, the relative changes in these three parameters are equal to each other:

$$
\% \mathrm{CC}^{-\mathrm{DS}_{\text {stage } 1}=\% \text { change in maximum shear stress }} \text { stage } 1_{1}=\% \text { change in } \mathrm{BSR}_{\text {stage } 1}
$$

Based on the discussions above, the maximum shear stress, BSR, and CC-DS values are monitored for the locations of all significant events during all stages of mining between 2006 and 2008, and compared to their pre-mining values.

\subsubsection{Event location cubes}

In the first phase of numerical analysis, the locations of all significant events are plotted in the mine-wide numerical model. The number and location of spatial clusters is then confirmed and a few are chosen for a detailed study. The different parameters assigned by the monitoring system at Garson Mine comprise the coordinates of each event and its location error. The latter is the maximum distance from the coordinates in any direction within which the actual location of the event lies. Hence, because of the 3D nature of the grid system, the coordinates and location error result in a sphere which contains the actual source of the event. In this study, these values for all the significant events are retrieved from the microseismic database, and are used to construct a location cube within which the actual event must lie. A cube is used instead of a sphere because of shape restrictions in FLAC3D. If it occurs at the boundary of several geological units, a location cube can comprise portions from different formations, and its size is determined by the value of the location error. An event cluster includes several location cubes, which can overlap each other if their coordinates are in close proximity and their location errors are large. As a sample, the location cube of the February 25, 2008 rockburst-causing event is graphically presented in Figure 2 . The coordinates of the event are given with the sides of the cube located at a distance equal to the location error reported by the monitoring system, resulting in a volume in which the true coordinates must lie. The figure also shows the actual model zones included within this location cube, comprising a number of geological formations. It is the mining-induced stresses of these zones that are used in the analysis that follows.

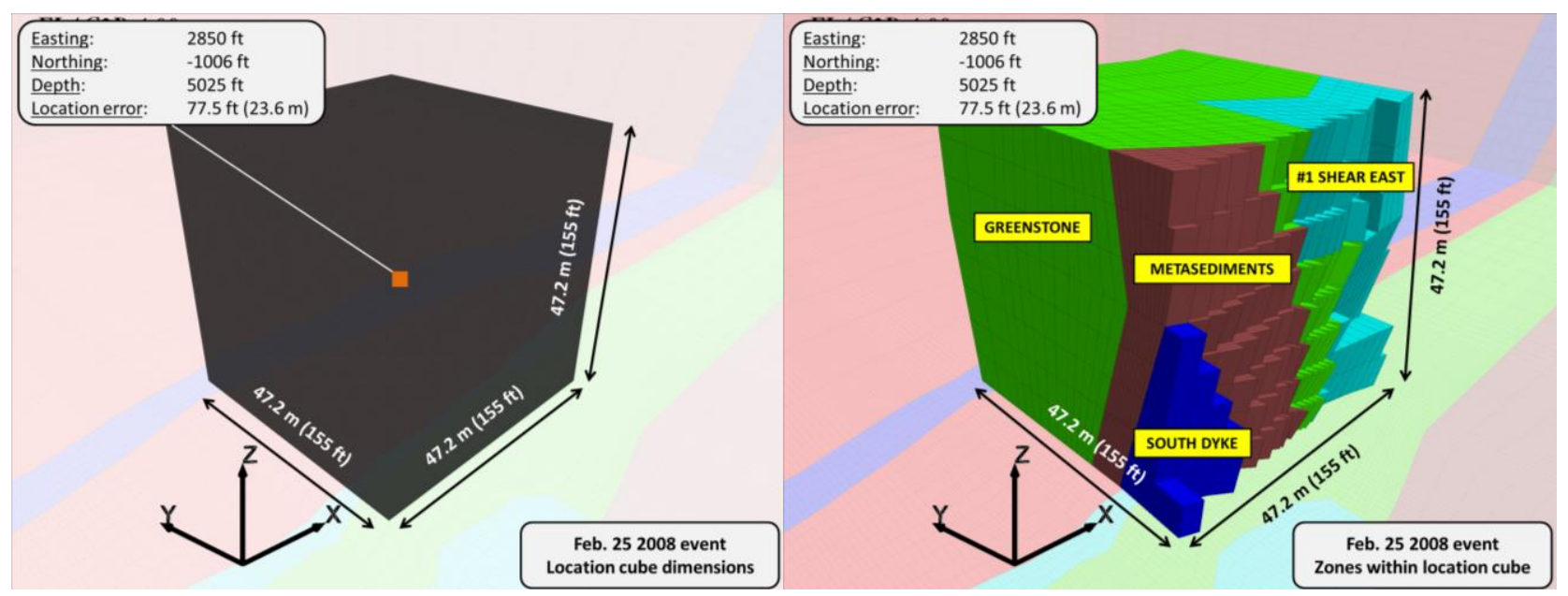

Figure 2 Location cube of sample event based on its coordinates and location error

Once the location cubes are plotted and several clusters are selected for detailed study, the maximum shear stress, BSR, and CC-DS values are monitored continuously to obtain typical trends. As a first step of analysis, they provide a quantitative assessment of mining-induced stress change signatures for the significant events. When these signatures are identified, it becomes a simpler task to look for them within the entire model to verify if those areas also experience microseismic activity. 


\subsection{Mining-induced stresses at active and quiet regions}

The examination of mining-induced stress change indicators within the location cubes forms the first part of a combined microseismic and numerical modelling analysis, and constitutes a back-analysis of events that have already taken place. Once the stress change signatures or trends are determined, the second phase of analysis attempts to verify if, had these signatures been known previously, they could have been used in predicting the relative susceptibility of an area to activity. In order to achieve this, the greenstone formation is divided into a number of vertical and horizontal regions. Vertically, the divisions are based on the mine levels and horizontally, it is divided into regions of $60 \mathrm{~m}$ length extending from Easting 1650 to Easting 3850 in the east-west direction. In terms of width in the north-south direction, the entire thickness of the formation, which is variable, is taken as a single division to simplify matters.

Based on these divisions, an analysis for stress change indicators is conducted for active regions that comprise clusters, and quiet ones that are far from them. The maximum shear stress, BSR, and CC-DS are monitored for an entire active region in the greenstone formation rather than simply in the location cube. The purpose is to observe if regions hosting the clusters also reflect similar stress change signatures, which would be an important step in developing a prediction method for microseismically active areas. In order to ascertain that those signatures are due to mining-induced stress changes and not due to depth, an additional region characterised by the absence of, and a maximum distance from, any clusters is also analysed.

\section{$5 \quad$ Results and discussion}

In order to follow the outline of the methodology presented in the previous sections, the results of each of the microseismic and numerical analysis phases are reported separately.

\subsection{Microseismic analysis}

The microseismic database retains tens of thousands of entries for events that have taken place during the study period between 2006 and 2008. Based on reports from the mine, nine rockbursts took place during these years. The date, time, and location of events that caused rockbursts in underground openings are retrieved from the microseismic database and presented in Table 1 along with their host geological formations, bearing in mind that these location coordinates may not always be close to areas where rock ejection took place.

Table 1 Details of rockburst-causing events at the Vale Garson Mine: 2006 to 2008

\begin{tabular}{|llllll}
\hline \multicolumn{2}{c}{ Date and time } & Easting & Northing & Depth $(\mathrm{m})$ & Geology \\
\hline $23 / 12 / 2006$ & $7: 12$ & $2,969.03$ & -799.48 & $-1,485.54$ & Interdyke norite \\
$23 / 01 / 2007$ & $21: 58$ & $2,687.46$ & -634.14 & $-1,417.12$ & North dyke \\
$25 / 02 / 2008$ & $16: 59$ & $2,849.90$ & $-1,005.89$ & $-1,531.54$ & Greenstone \\
$25 / 03 / 2008$ & $11: 17$ & $2,736.97$ & -598.77 & $-1,445.95$ & North dyke \\
$06 / 04 / 2008$ & $1: 06$ & $2,727.96$ & -583.10 & $-1,466.73$ & North dyke \\
$22 / 06 / 2008$ & $20: 49$ & $3,174.04$ & $-1,000.83$ & $-1,505.79$ & Greenstone \\
$25 / 06 / 2008$ & $12: 07$ & $2,430.04$ & -757.61 & $-1,516.60$ & \#4 Shear East \\
$09 / 09 / 2008$ & $18: 55$ & $2,889.13$ & $-1,036.16$ & $-1,543.19$ & Greenstone \\
$05 / 12 / 2008$ & $13: 36$ & $2,835.10$ & -959.07 & $-1,546.60$ & Greenstone \\
\hline
\end{tabular}

2008 was an active year as can be observed from the table with all but two of the nine events having occurred in it. In terms of geological formations, it can be noted that the north dyke and greenstone formations host seven of the nine rockburst-causing events, making them prime targets for further analysis. 
Furthermore, while the former is seen to host events at shallower levels $(1,415$ to $1,465 \mathrm{~m})$, the latter is responsible for deeper microseismic activity (1,505 to $1,550 \mathrm{~m})$.

As explained previously, occurrences with energy outputs greater than $100 \mathrm{~kJ}$ are designated as large events for this study provided their location errors are less than $30 \mathrm{~m}$. During the three year period, 15 events with these characteristics took place. An analysis of this set shows that apart from the two active formations identified in Table 1, the interdyke norite also hosts significant microseismicity. From the 15 large events, six occur within this particular formation while the greenstone and north dyke units each host three of them. Hence, from a total set of 24 significant events, seven take place within the greenstone formation, seven within the interdyke norite, and six within the north dyke, for a total of 20 . It is therefore a simple conclusion that these three formations need to be studied further in terms of numerical analysis to verify any patterns that might explain the frequent microseismicity in them.

When the 24 significant events are plotted in the mine-wide model, they combine to form a number of spatial clusters. A cluster is located within each of the greenstone, interdyke norite, and north dyke formations, while a fourth one that is made up of only large events is present at the junction of these three formations in the west. The four clusters are identified in Figure 3 and the details are given in Table 2 for all rockburst-causing (RB) or large events 'LE'. For the purposes of this paper, only the first and third clusters are examined.

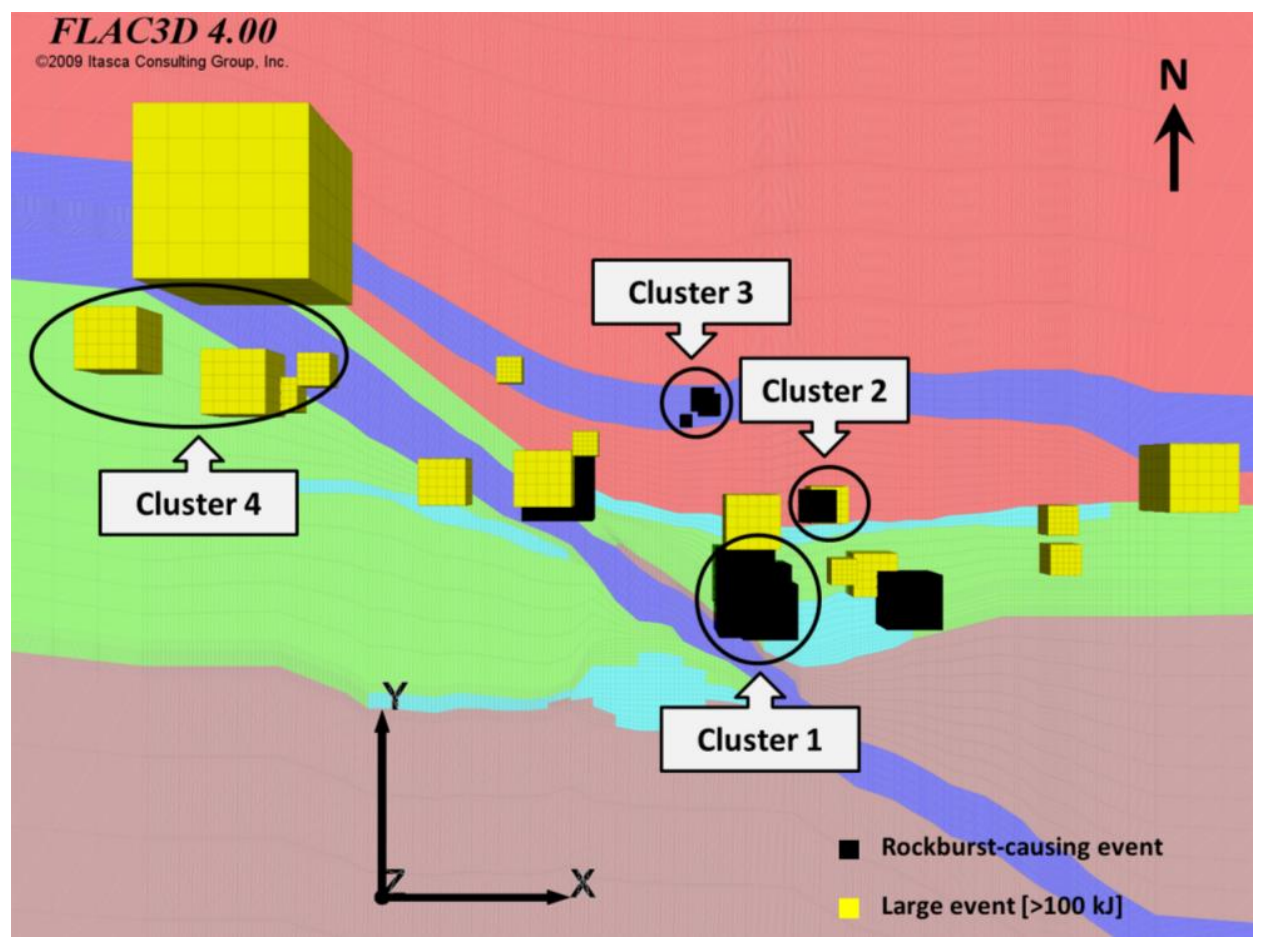

Figure 3 Clusters formed by rockburst-causing and large events

Clusters 1 and 3 are each made up of three rockburst-causing events, which are chronologically separated by 10-15 months. While their locations are close enough to indicate a seismically susceptible area, and the timing of the different events are more than a year apart, a numerical analysis is required to examine the possible mechanisms that trigger them. Hence, the proximity to the mining front at the time, and changes in mining-induced stresses are the focal point of analysis in the following section.

Table 2 Details of the four microseismic clusters

\begin{tabular}{cccccc}
\hline Date and time & ID & Easting & Northing & Depth (m) & Geology \\
\hline Cluster 1 & & & &
\end{tabular}




\begin{tabular}{|c|c|c|c|c|c|c|}
\hline $25 / 02 / 2008$ & $16: 59$ & RB 1 & $2,849.90$ & $-1,005.89$ & $-1,531.54$ & Greenstone \\
\hline 09/09/2008 & $18: 55$ & RB 2 & $2,889.13$ & $-1,036.16$ & $-1,543.19$ & Greenstone \\
\hline $05 / 12 / 2008$ & $13: 36$ & RB 3 & $2,835.10$ & -959.07 & $-1,546.60$ & Greenstone \\
\hline \multicolumn{7}{|c|}{ Cluster 2} \\
\hline $23 / 12 / 2006$ & $7: 12$ & RB & 2,969.03 & -799.48 & $-1,485.54$ & Interdyke norite \\
\hline $01 / 05 / 2007$ & $14: 03$ & LE & $2,993.22$ & -797.82 & $-1,495.30$ & Interdyke norite \\
\hline \multicolumn{7}{|c|}{ Cluster 3} \\
\hline $23 / 01 / 2007$ & $21: 58$ & RB 1 & $2,687.46$ & -634.14 & $-1,417.12$ & North dyke \\
\hline $25 / 03 / 2008$ & $11: 17$ & RB 2 & $2,736.97$ & -598.77 & $-1,445.95$ & North dyke \\
\hline 06/04/2008 & 1:06 & RB 3 & $2,727.96$ & -583.10 & $-1,466.73$ & North dyke \\
\hline \multicolumn{7}{|c|}{ Cluster 4} \\
\hline $23 / 01 / 2006$ & $17: 23$ & LE 1 & $1,924.40$ & -579.83 & $-1,360.94$ & 4 Shear East \\
\hline 09/08/2007 & $19: 45$ & LE 2 & $1,976.42$ & -595.26 & $-1,378.84$ & Greenstone \\
\hline 09/08/2007 & $19: 45$ & LE 3 & $2,034.01$ & -551.45 & $-1,378.75$ & Interdyke norite \\
\hline $29 / 02 / 2008$ & $5: 26$ & LE 4 & $1,730.74$ & -512.08 & $-1,348.24$ & Interdyke norite \\
\hline
\end{tabular}

\section{$5.2 \quad$ Numerical analysis}

The mine-wide numerical model replicates the historical mining sequence followed at the mine from 2001 to 2008 in three month stages, and the proximity of the significant events within the clusters to the mining front at the time can be assessed easily. The percentage of nearby stope volume extracted during each stage is recorded to check for any correlations with the timings of these events. As explained previously, the maximum shear stress, BSR, and CC-DS are also monitored. The results for the two clusters studied in this paper are given in the following sections.

\subsubsection{Cluster 1}

This cluster is located at a depth of about $1,540 \mathrm{~m}$ within the greenstone formation and is made up of three rockburst-causing events (RB) that took place in February, September, and December of 2008. It is located at the boundary between the greenstone formation and the \#1 Shear East orebody at those depths, and could therefore be caused by mining activities in its vicinity. Using the location cubes of each event within the cluster, the average values of maximum shear stress, BSR, and CC-DS within greenstone zones between $5100 \mathrm{~L}$ and $5000 \mathrm{~L}$ in the cubes are presented in Table 3, in addition to the relative percentage of ore extracted from the nearby stopes.

In terms of maximum shear stress, it can be observed that the pre-mining values are around $18 \mathrm{MPa}$ in the greenstone formation within all three location cubes. The BSR, on the other hand, stands at around 0.21, which does not indicate any strainburst potential according to the guidelines given by Castro et al. (2012), falling far short of the 0.7 threshold. From the evolution of the mining front, it can be seen that operations in the vicinity commence in the second quarter of 2007 with the extraction of about $13 \%$ of the ore in the closest stopes, and continues until the end of the study period when about $45 \%$ is extracted.

Table 3 Cluster 1: average values of maximum shear stress, BSR, and CC-DS

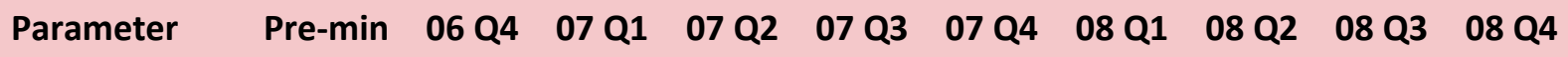




\begin{tabular}{|c|c|c|c|c|c|c|c|c|c|c|}
\hline RB 1 & & & & & & & & & & \\
\hline CC-DS (\%) & 0.00 & 4.07 & 3.86 & 25.93 & 28.34 & 29.19 & 30.65 & 31.25 & 32.15 & 32.23 \\
\hline Max shear (MPa) & 17.87 & 18.30 & 18.27 & 22.36 & 22.77 & 22.92 & 23.18 & 23.28 & 23.45 & 23.46 \\
\hline BSR & 0.21 & 0.21 & 0.21 & 0.26 & 0.26 & 0.27 & 0.27 & 0.27 & 0.27 & 0.27 \\
\hline \multicolumn{11}{|l|}{ RB 2} \\
\hline CC-DS (\%) & 0.00 & 2.29 & 2.04 & 43.68 & 48.65 & 50.77 & 54.31 & 56.16 & 60.50 & 60.86 \\
\hline Max shear (MPa) & 18.12 & 18.32 & 18.30 & 24.99 & 25.84 & 26.20 & 26.84 & 27.16 & 27.98 & 28.04 \\
\hline BSR & 0.21 & 0.21 & 0.21 & 0.29 & 0.30 & 0.30 & 0.31 & 0.32 & 0.33 & 0.33 \\
\hline \multicolumn{11}{|l|}{ RB 3} \\
\hline CC-DS (\%) & 0.00 & 2.90 & 2.91 & 8.14 & 8.75 & 8.82 & 8.99 & 8.78 & 8.88 & 8.69 \\
\hline Max shear (MPa) & 18.42 & 18.86 & 18.87 & 19.83 & 19.95 & 19.96 & 19.99 & 19.95 & 19.98 & 19.94 \\
\hline BSR & 0.22 & 0.22 & 0.22 & 0.23 & 0.23 & 0.23 & 0.23 & 0.23 & 0.23 & 0.23 \\
\hline \multicolumn{11}{|l|}{ Mining front } \\
\hline$\%$ volume mined & 0.00 & 0.00 & 0.00 & 12.73 & 18.38 & 24.23 & 31.89 & 39.00 & 44.79 & 44.79 \\
\hline
\end{tabular}

Concurrent with mining operations, the maximum shear stress rises to 23 and $25 \mathrm{MPa}$ in RB 1 and RB 2, respectively, and to $20 \mathrm{MPa}$ in $\mathrm{RB} 3$. On the other hand, BSR values rise to 0.26 and 0.29 in the first two location cubes, and a minor change is recorded in RB 3 where it reads 0.22 . They continue to rise with the continuation of mining in the vicinity and reach values of $0.27,0.33$, and 0.23 in RB $1, R B 2$, and RB 3 , respectively, at the end of 2008. All of these numbers fall within a range that expects only minor surface spalling damage to the rock mass with no potential for strainbursting according to the guidelines.

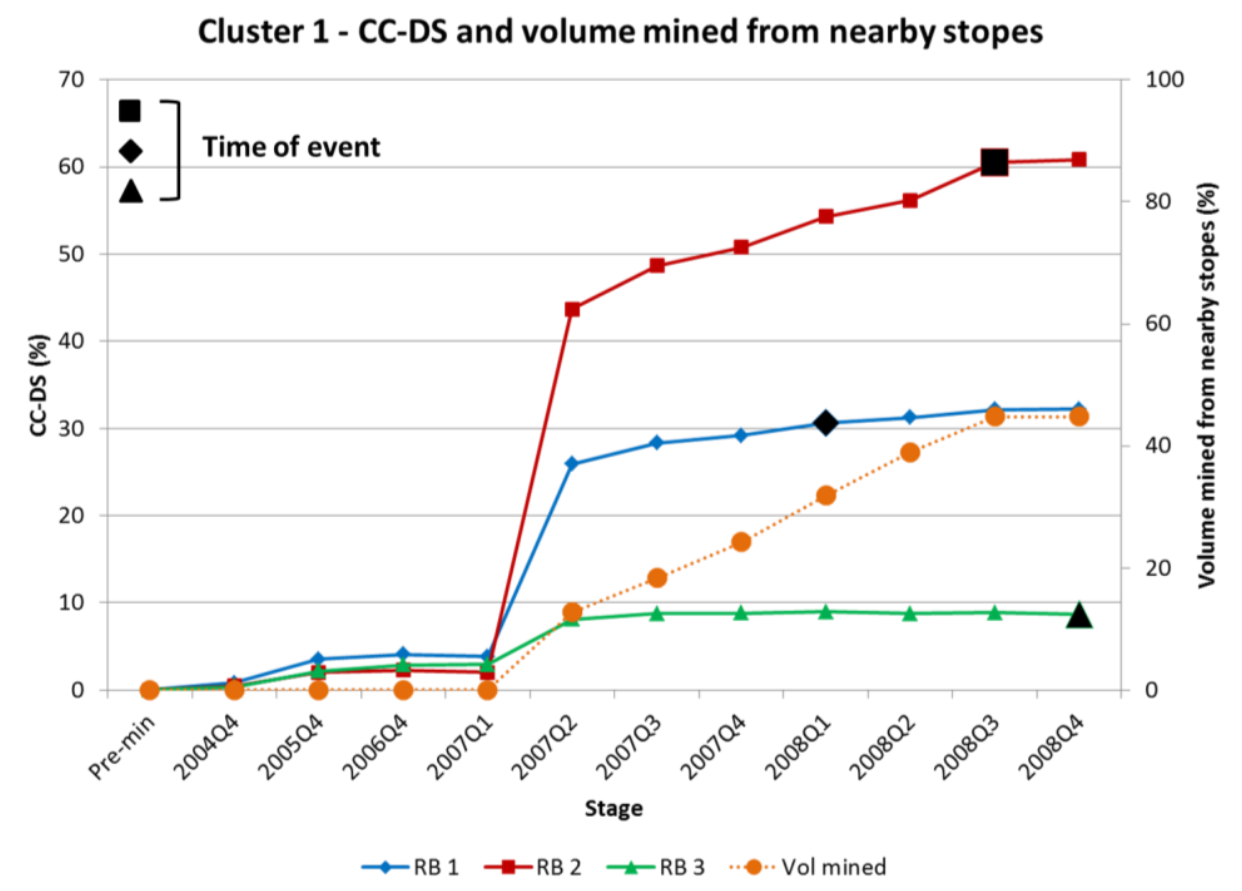

Figure 4 Cluster 1: CC-DS values and volume mined from nearby stopes

However, the CC-DS values clearly indicate sharp changes in the differential stress compared to pre-mining conditions within the location cubes, which commences with the start of mining in the vicinity. To better 
visualise the changes, CC-DS values for the events in Cluster 1 are plotted against the mining advance nearby in Figure 4, with the time of the event indicated by a large dark marker on each line.

It can be observed that while the absolute values of differential stress, as presented by the maximum shear and BSR numbers, register an increase with the onset of mining activities, they do not carry any indications that a certain threshold has been crossed to justify the occurrence of events. The CC-DS value, because it monitors the differential stress evolution and compares it to pre-mining conditions, shows a steep rise as soon as the first mining activities start in the vicinity. Values rise from just under 4 to 26,44 , and $8 \%$ in RB 1, RB 2, and RB 3, respectively, and continue to either increase gently or remain at that level until the end of the study period. All three rockburst-causing events take place at elevated levels of CC-DS during the first, third, and fourth quarters of 2008. In terms of ore mined from nearby stopes, the dashed orange line in Figure 4 starts to rise continuously from the second quarter of 2007 onwards, and reaches a plateau of about $45 \%$ in the third quarter of 2008. It is interesting to note that the extraction of stopes at the time of all three events is either on the rise or has reached its ultimate plateau.

\subsubsection{Cluster 3}

Cluster 3 is located completely within the north dyke formation. Furthermore, it is the furthest cluster from any mining fronts amongst the ones identified in this paper. While Cluster 1 is clearly related to mining activities due to its location and the timing of its events, the distance of Cluster 3 from orebodies suggests that its events are not related to stope extraction.

When the details of the individual events within this cluster are calculated from the model outputs, the first observation is the absence of mining operations in this region, confirming that the events are not related to them. Maximum shear stress values start at $27 \mathrm{MPa}$ in all three location cubes and increase gradually to reach maximum levels of $29 \mathrm{MPa}$ at the end of the study period. In terms of BSR values, they commence at 0.27 and reach their maximum of 0.30 at the end of 2008, falling within the same range as those of Cluster 1 with no potential for strainbursts indicated.

The CC-DS values for the north dyke are presented in Figure 5, showing their relative change with respect to the pre-mining conditions. All three events show similar patterns despite their occurrence at different depths. They show a slight increase at the end of 2005, followed by a similar rate of increase at the end of 2006. The highest levels are attained in the second half of 2007 for RB 1, RB 2, and RB 3 at 12, 9, and 5\% increase respectively in CC-DS. After this time, the rates decrease slightly due to a decrease in differential stress, a trend that is also evident from the maximum shear stress and BSR values. Although not as high as the ones in Cluster 1 in the greenstone formation, increases in CC-DS are nevertheless noteworthy since they take place between 2005 and 2006. This indicates some relationship to mining activities in \#4 Shear East, though not on the levels of interest for this cluster, which would also explain the relatively low percentages of increase.

It is clear that the CC-DS value is able to monitor the changes in differential stress due to mining, and give a quantitative assessment of it at any location within the mine-wide model. It is therefore not restricted to zones close by or adjacent to extracted stopes, and is able to evaluate changes in the stress regime due to mining-related activities rather than only absolute values that would require previously set guidelines for comparison. By using the pre-mining values as the basis, restrictions as to the method's applicability in only certain conditions or for specific rock mass properties are thus removed.

It should also be noted that Cluster 3 occurs close to the location of major north-south drifts running from the norite formation in the north to the greenstone formation in the south, which cut across all the geological units in between. Drifts and mine developments are not included in this model as they are the focus of another part of the project. However, even without their inclusion, sudden increases are already observed in CC-DS values, indicating stress changes. 
Cluster 3 - CC-DS and volume mined from nearby stopes

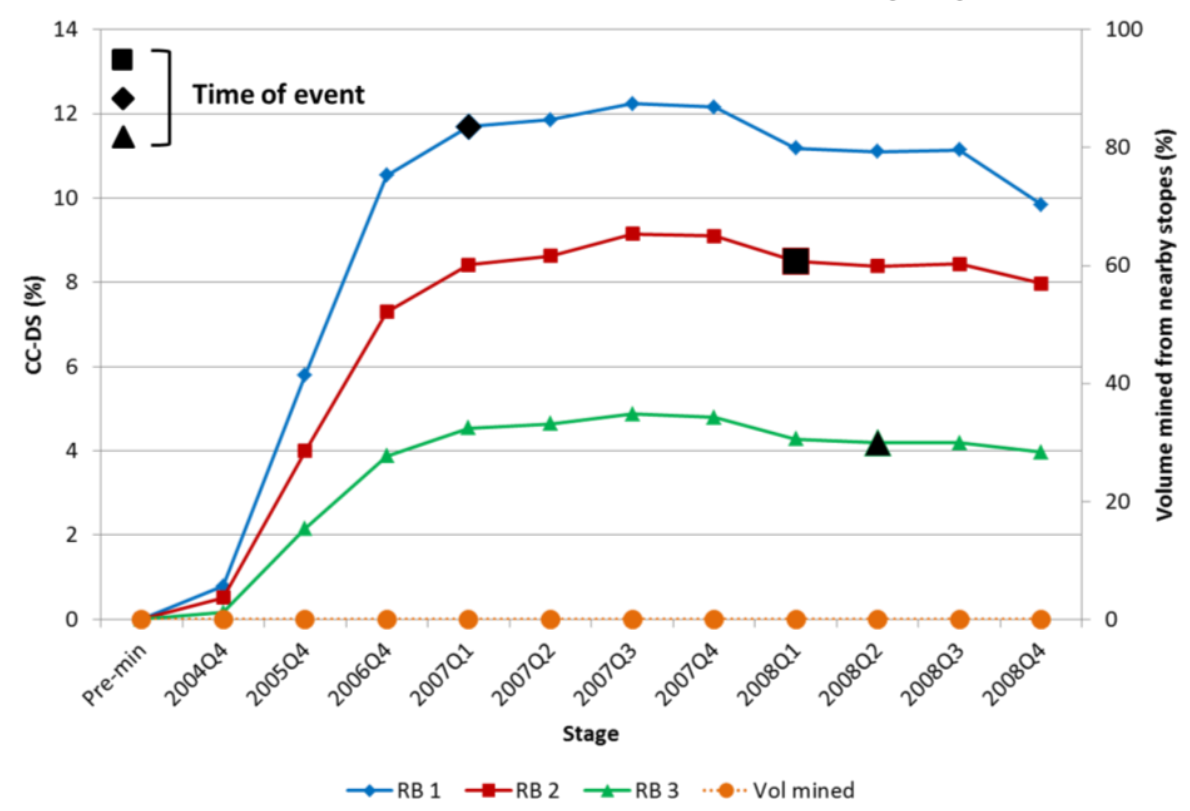

Figure 5 Cluster 3: CC-DS values and volume mined from nearby stopes

\subsubsection{Active and inactive regions}

Changes in differential stress within event location cubes correlate well with their timing, and steep increases in the CC-DS values always occur in those zones some time prior to or at the time of the event itself. The sections above presented an analysis of six rockburst-causing events and their CC-DS signatures during the study period. While this constitutes a back-analysis of significant events, it needs to be verified if the CC-DS signatures hold any potential for prediction. Hence, if a steep increase in CC-DS is a precursor to significant events in an area, it needs to be seen if regions within a model can be searched for such values at a given stage during a planned stope sequence in order to predict the occurrence of significant events there. If it can indeed be used for such a function, then the next step would be to determine CC-DS thresholds at which a significant event could occur in a specific formation or at a certain depth.

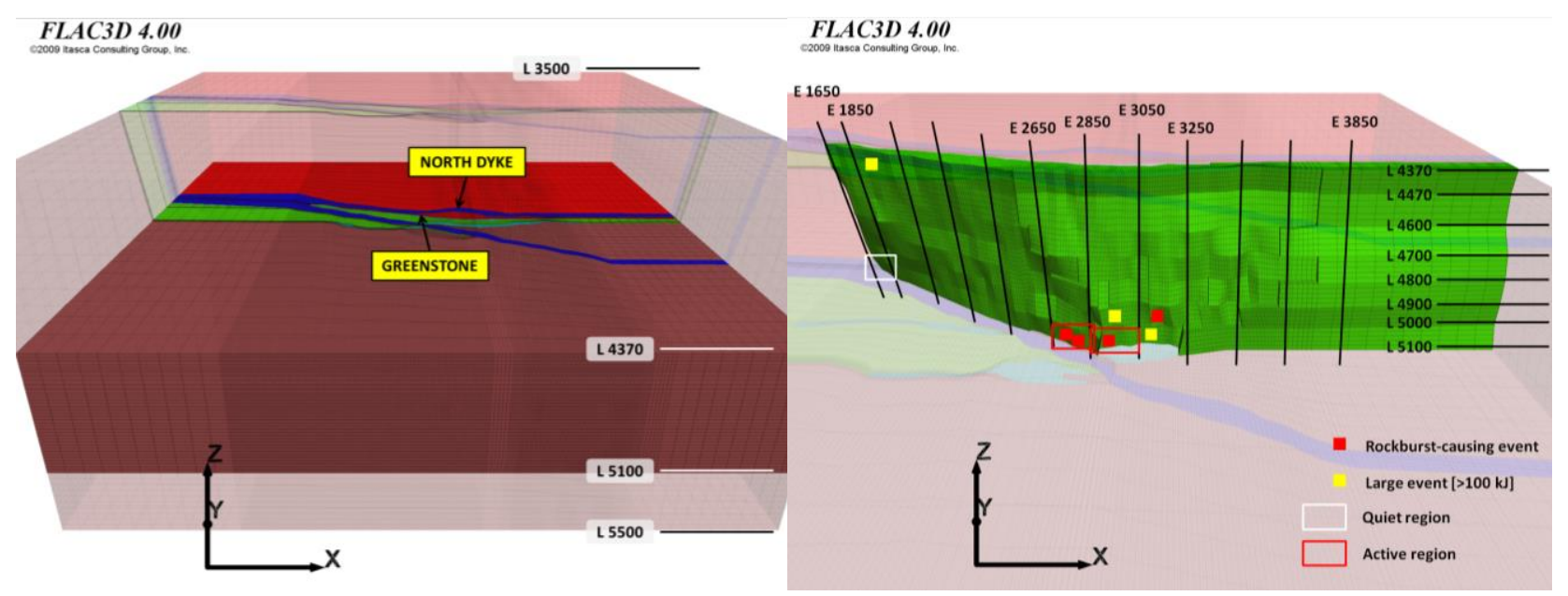

Figure 6 Greenstone formation: location of active and quiet regions

To test this proposition, the greenstone formations, which host Clusters 1, is divided into regions of $60 \mathrm{~m}$ in the east-west direction. The vertical dimension used is the one determined by the levels, which is usually $30 \mathrm{~m}$. The east-west direction in this part of the study extends from E 1650 to E 3850, giving a total of 11 regions in this direction, and the vertical extent runs from $5100 \mathrm{~L}$ to $4470 \mathrm{~L}$, providing six regions in that direction. The total number of regions is therefore 66 , and significant events within the greenstone unit are 
indicated graphically in Figure 6. Based on their coordinates, the most active regions in this formation extends from E 2650 to E 3250 between $5100 \mathrm{~L}$ and 5000L (three horizontally adjacent regions).

Based on this assessment, the CC-DS values for the region bordered by levels 5100 and 5000 between E 2650 and E 2850 are plotted, which is where RB 1 and RB 3 (Cluster 1) occur. The timing of RB 2 in the adjacent region is also indicated due to its occurrence at less than $13 \mathrm{~m}$ from the active one. A quiet region with no significant event is also selected for comparison purposes, which is the region defined by $E 1650$ and $E 1850$ at the same depth. To accentuate the signatures of stress change within a region, maximum CC-DS values for each stage are used instead of average ones. The trends are presented in Figure 7, indicating the timing of rockburst-causing events within the active region and in the adjacent one (E 2850 to $\mathrm{E} 3050)$.

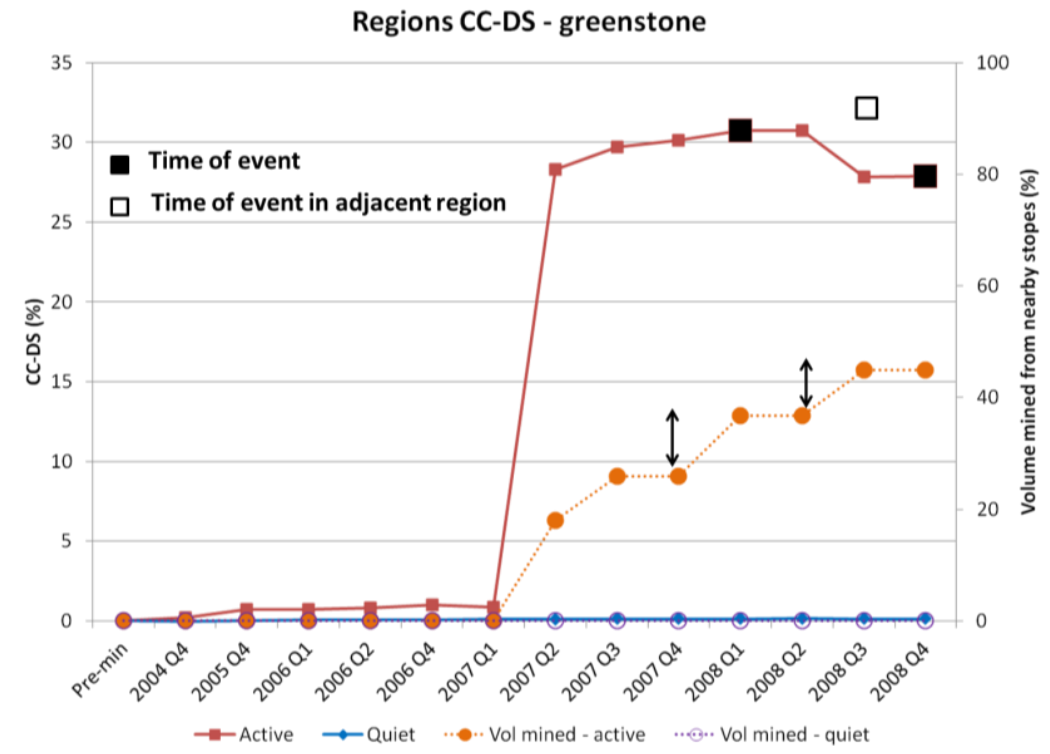

Figure 7 Greenstone: CC-DS trends in active and quiet regions

It can be clearly observed that the CC-DS trends match with the microseismic activities in the active region. The most significant rise is observed with the onset of mining in the second quarter of 2007 but without any significant events taking place afterwards. The first rockburst-causing event occurs in the first quarter of 2008, immediately after a small increase in mined volume as indicated by a vertical arrow. Another increase occurs in the second quarter of 2008 , which is followed by a rockburst-causing event in the adjacent region, and by another one in the study region. The small increases in volume mined from nearby stopes are both followed by significant events, indicating the capability of the CC-DS method to designate a region as potentially prone to microseismic activity. On the other hand, the quiet zone does not show any changes in the stress regime and no stopes are present in the vicinity to constitute a mining front. Therefore, the CC-DS parameter is independent of the depth of the study region and is not influenced by the higher stress regime there if no changes are incurred.

In order to illustrate the evolution of CC-DS in an active zone, readings in the two regions in the greenstone formation between E 2650 and E 3050, and between 5100L and 5000L, are plotted in Figure 8 during 2007 and 2008. In addition to the greenstone unit in these two regions, some of the first stopes to be extracted on this level are also shown.

It can be observed that until the onset of mining in the area in the second quarter of 2007, the CC-DS remains virtually unaltered. With the extraction of the first stopes, an envelope of sudden changes in the CC-DS is seen to encompass the voids created. As mining continues, the envelope becomes larger, and in the final quarter of that year, a large event location cube can be seen at the top right corner of the active regions. The location cube of RB 1 in Cluster 1 can be observed in the first quarter of 2008 around the position of the first stope extracted on this level. RB 2 and RB 3 are observed very close to it later on in that year as the envelope of CC-DS increase expands eastwards. 


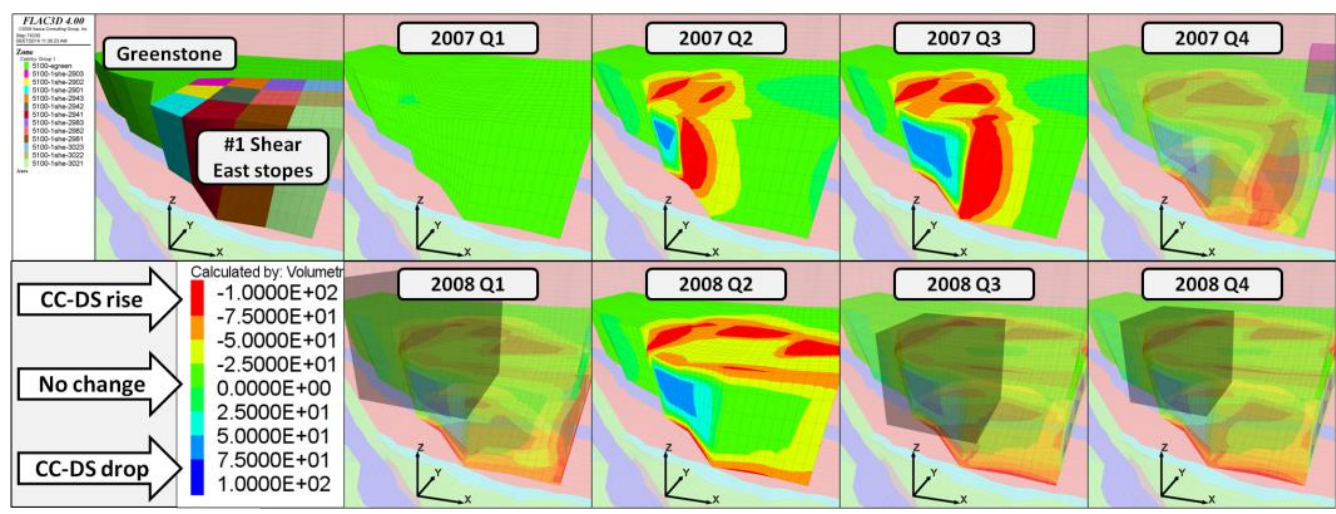

Figure 8 Greenstone: CC-DS in active regions - E 2650 to E $3050 /$ Levels 5100 to 5000

Based on this, the CC-DS method holds a promising potential to be further developed and transformed from a back-analysis tool to one that can be used for designating active and quiet zones in terms of future microseismic activity. Furthermore, it is a dynamic tool that evolves with the ever-changing stress regime in the field. More work needs to be done in this regard in order to determine several practical criteria such as critical CC-DS ranges for different formations, and the time delay between a rise in the CC-DS and an event.

\section{Conclusions}

A combined microseismic and numerical modelling analysis is conducted for the Vale Garson Mine in terms of rockburst-causing and large events from 2006 to 2008. The group of 24 significant events is observed to form four spatial clusters within three key geological formations, and two of the clusters are studied in detail. The events in the greenstone and north dyke formations are plotted as location cubes based on their coordinates and location errors, and the zones within are examined for the maximum shear stress, BSR, and CC-DS values. While changes in the first two parameters are observed, the values attained do not necessarily pass a threshold that would be indicative of potential microseismic events. The CC-DS values show clear increases associated with readjustments in stresses generally, and near mining fronts specifically. All events are observed to take place either during an increase in CC-DS or afterwards, although some of the events occur after 12 or 18 months. Based on these results, and using a predictive rather than back-analysis approach, active and quiet regions within the greenstone formation - spanning $60 \mathrm{~m}$ in the east-west direction, $30 \mathrm{~m}$ vertically, and along the entire width in the north-south direction - are defined and studied in terms of CC-DS trends. The results show that while the active region exhibits the same sudden increases observed in the location cubes, the quiet one typically shows an almost nil percentage change in the CC-DS.

\section{Acknowledgement}

This work is financially supported by a research grant from the Natural Sciences and Engineering Research Council of Canada in partnership with Vale Ltd. (CRD Program). The authors are grateful for their financial support. Dr Denis Thibodeau, formerly Principal Consultant Rock Mechanics at Vale, is specially acknowledged for his support and technical input during the course of the project.

\section{References}

Abdul-Wahed, MK, Al Heib, M \& Senfaute, G 2006, 'Mining-induced seismicity: seismic measurement using multiplet approach and numerical modelling', International Journal of Coal Geology, vol. 66, no. 1-2, pp. 137-147.

Bewick, RP, Valley, B, Runnalls, S, Whitney, J \& Krynicki, Y 2009, 'Global approach to managing deep mining hazards', in M Diederichs \& G Grasseli (eds), Proceedings of the Third Canada-US \& Twentieth Canadian Rock Mechanics Symposium: ROCKENG09, University of Toronto, Toronto, paper 3994.

Brace, WF, Paulding, BW Jr \& Scholz, C 1966, 'Dilatancy in the fractures of crystalline rocks', Journal of Geophysical Research, vol. 71, no. 16, pp. 3939-3953.

Brady, BHG \& Brown, ET 2006, Rock Mechanics for Underground Mining, 3rd edn, Springer, Dordrecht. 
Castro, LAM 1996, Analysis of stress-induced damage initiation around deep openings excavated in a moderately jointed brittle rock mass, PhD thesis, University of Toronto, Toronto.

Castro, LAM, Bewick, RP \& Carter, TG 2012 'An Overview of Numerical Modelling Applied to Deep Mining', in R Azevedo (ed.), Innovative Numerical Modelling in Geomechanics, CRC Press - Taylor \& Francis Group, London.

Castro, LAM, McCreath, DR \& Oliver, P 1996, 'Rockmass damage initiation around the Sudbury neutrino observatory cavern', in M Aubertin, FP Hassani \& H Mitri (eds), Second North American Rock Mechanics Symposium, American Rock Mechanics Association, Alexandria, pp. 1589-1595.

Castro, LAM, Grabinsky, MW \& McCreath, DR 1997, 'Damage initiation through extension fracturing in a moderately jointed brittle shear rock mass', International Journal of Rock Mechanics and Mining Sciences, vol. 34, no. 3-4, pp. 110e.1-e13.

Cook, NGW 1976, 'Seismicity associated with mining', Engineering Geology, vol. 10, no. 2-4, pp. 99-122.

Diederichs, MS 1999, Instability of Hard Rock Masses: the Role of Tensile Damage and Relaxation, PhD thesis, University of Waterloo, Ontario.

Gibowicz, SJ 1990, 'Seismicity induced by mining', Advances in Geophysics, vol. 32, pp. 1-74.

Gibowicz, SJ \& Lasocki, S 2000, 'Seismicity induced by mining: ten years later', Advances in Geophysics, vol. 44, pp. 39-181.

Hasegawa, HS, Wetmiller, RJ \& Gendzwill, DJ 1989, 'Induced seismicity in mines in Canada - an overview', Pure and Applied Geophysics, vol. 129, no. 3-4, pp. 423-453.

Hazzard, JF \& Young, RP 2004, 'Dynamic modelling of induced seismicity', International Journal of Rock Mechanics and Mining Sciences, vol. 41, no. 8, pp. 1365-1376.

Hudyma, MR 2008, Analysis and Interpretation of Clusters of Seismic Events in Mines, PhD thesis, The University of Western Australia, Perth.

Itasca Consulting Group, Inc. 2014, FLAC3D: Fast Lagrangian Analysis of Continua in 3 Dimensions, Itasca Consulting Group, Inc., Minneapolis, http://www.itascacg.com/software/flac3d

Jaeger, JC, Cook, NGW \& Zimmerman, RW 2007, Fundamentals of Rock Mechanics, 4th edition, Blackwell Publishing Limited, Oxford.

Kijko, A \& Funk, CW 1996, 'Space-time interaction amongst clusters of mining induced seismicity', Pure and Applied Geophysics, vol. 147, no. 2, pp. 277-288.

Maloney, S \& Cai, M 2006, In situ stress determination - Garson Mine, MIRARCO Project report 06-015, Mining Innovation Rehabilitation and Applied Research Corporation (MIRARCO), Sudbury.

Marsan, D, Bean, CJ, Steacy, S \& McCloskey, J 1999, 'Spatio-temporal analysis of stress diffusion in a mining-induced seismicity system', Geophysical Research Letters, vol. 26, no. 24, pp. 3697-3700.

Martin, CD \& Chandler, NA 1994, 'The progressive fracture of Lac-du-Bonnet granite', International Journal of Rock Mechanics and Mining Sciences \& Geomechanics Abstracts, vol. 31, no. 6, pp. 643-659.

Martin, CD 1997, 'Seventeenth Canadian Geotechnical Colloquium: the effect of cohesion loss and stress path on brittle rock strength', Canadian Geotechnical Journal, vol. 34, no. 5, pp. 698-725.

Martin, CD, Kaiser, PK \& McCreath, DR 1999 'Hoek-Brown parameters for predicting the depth of brittle failure around tunnels', Canadian Geotechnical Journal, vol. 36, no. 1, pp. 136-151.

McGarr, A, Simpson, D \& Seeber, L 2000, 'Case histories of induced and triggered seismicity', in PC Jennings, H Kanamori \& WHK Lee (eds), International Handbook of Earthquake and Engineering Seismology Part A, Academic Press, Waltham.

McKinnon, SD 2006, 'Triggering of seismicity remote from active mining excavations', Rock Mechanics Rock Engineering, vol. 39, no. 3, pp. 255-279.

Mendecki, AJ 1993, 'Real time quantitative seismology in mines: keynote lecture', in RP Young (ed.), Proceedings of the Third International Symposium on Rockburst and Seismicity in Mines, Balkema, Rotterdam, pp. 287-296.

Mercer, RA \& Bawden, WF 2005a, 'A statistical approach for the integrated analysis of mine induced seismicity and numerical stress estimates, a case study - Part I: developing the relations', International Journal of Rock Mechanics and Mining Sciences, vol. 42, no. 1, pp. 47-72.

Mercer, RA \& Bawden, WF 2005b, 'A statistical approach for the integrated analysis of mine induced seismicity and numerical stress estimates, a case study - Part II: evaluation of the relations', International Journal of Rock Mechanics and Mining Sciences, vol. 42, no. 1, pp. 73-94.

Mikula, P, Heal, D, Hudyma, M \& Potvin, Y 2008, 'Generic seismic risk management plan for underground hardrock mines', Phase Three Mine Seismicity and Rockburst Risk Management (MSRRM) Project, 2006-2008 Technical Report, prepared by Australian Centre for Geomechanics, Perth.

Spottiswoode, SM 1989, 'Perspectives on seismic and rockburst research in the South African gold mining industry: 1983-1987', Pure and Applied Geophysics, vol. 129, no. 3-4, pp. 673-80.

Vasak, P, Suorineni, FT, Kaiser, PK \& Thibodeau, D 2004, 'Hazard map approach using space-time clustering analysis of mineinduced microseismicity', Proceedings of the Annual Canadian Institute of Mining, Metallurgy \& Petroleum Conference Mining North, Canadian Institute of Mining, Metallurgy \& Petroleum, Westmount.

Verdon, JP, Kendall, J-M, White, DJ \& Angus, DA 2011, 'Linking microseismic event observations with geomechanical models to minimise the risks of storing $\mathrm{CO}_{2}$ in geological formations', Earth and Planetary Science Letters, vol. 305, no. 1-2, pp. 143-52.

Wiles, TD, Lachenicht, R \& van Aswegen, G 2001, 'Integration of deterministic modelling with seismic monitoring for the assessment of rockmass response to mining: Part I - Theory', in G van Aswegen, RJ Durrheim \& WD Ortlepp (eds), Proceedings of the Fifth International Symposium on Rockburst and Seismicity in Mines, South African Institute of Mining and Metallurgy, Johannesburg, pp. 379-387. 